\title{
Política de Saúde no Brasil e estratégias regulatórias em ambiente de mudanças tecnológicas *
}

José Mendes Ribeiro ${ }^{1}$ Nilson do Rosário Costa ${ }^{2}$ Pedro Luís Barros Silva ${ }^{3}$

RIBEIRO, J.M, COSTA, N.R., SILVA, P.L.B. Healthcare policies in Brazil and regulatory strategies in an environment of technological changes, Interface _ Comunicação, Saúde, Educação, v.4 , n.6, 2000.

This article examines regulatory policies currently in force, involving both the market for supplementary healthcare and the relations between the public administration, as well as the entities that provide services to sus (the Unified Healthcare System). Discusses the specificities of the healthcare sector vis a vis those industries that are subject to new operating models, such as telecommunication, or the electrical and oil industries, and the trend toward more responsive and better adjusted regulatory policies as regards SUS and Supplementary Healthcare.

KEY-WORDS: healthcare policies; organizational innovation; organizational models; technological development; public administration; legislation.

$\mathrm{O}$ artigo discute as políticas regulatórias em curso que envolvem tanto o mercado expresso pelo setor de saúde suplementar como as relações entre a administração pública e os prestadores de serviço junto ao Sistema único de Saúde (SUS). Aponta as especificidades do setor saúde frente às indústrias submetidas a novos regimes, como telecomunicações, setor elétrico e de petróleo, e a tendência a adoção de políticas reguladoras responsivas e mais pactuadas relacionadas ao SUS e à Saúde Suplementar.

PALAVRAS-CHAVE: política de saúde; inovação organizacional; modelos organizacionais; desenvolvimento tecnológico; administração pública; legislação.

\footnotetext{
*Artigo elaborado a partir da pesquisa Reforma do Estado e Setor Saúde, Relatório (Nepp/Unicamp; Ensp/Fiocruz; UfPe), financiada pela Capes/Finep/Cnpq e do relatório elaborado para a Cooperação Brasil-Reino Unido.

${ }^{1,2}$ Escola Nacional de Saúde Pública, Fundação Oswaldo Cruz, ENSP/Fiocruz.

${ }^{3}$ Núcleo de Estudos em Políticas Públicas, Nepp, Universidade Estadual de Campinas, Unicamp.
} 


\section{Introdução}

As políticas regulatórias praticadas no Brasil em diversos setores da economia e do aparelho estatal sofreram profundas alterações ao longo da década de noventa. $\mathrm{O}$ ritmo acelerado das transformações tecnológicas e o ambiente nacional e internacional de reforma do setor público alteraram o perfil básico da regulação no sentido de torná-la mais especializada $e$ adaptada aos casos. Os códigos devem repercutir as inovações tecnológicas, reduzindo o alcance de normas duradouras, ao menos enquanto fundamento da boa regulação. Por sua vez, a reforma do aparelho do estado vem produzindo, pelo modelo de agências, uma combinação entre especialidade técnica e insulamento burocrático de seus dirigentes como meio de obter maior eficiência econômica, ganhos em welfare e controle da captura dos reguladores por indústrias e serviços.

Este artigo discute a introdução de novos regimes regulatórios federais e seu equilíbrio com as práticas tradicionais no setor saúde no Brasil em ambiente de reforma do aparelho de estado e de mudanças tecnológicas. São apontadas tendências e recomendações voltadas a combinar o universalismo normativo característico das instituições públicas com sua adequação ao rápido desenvolvimento tecnológico e diferenciação na produção de serviços.

A reforma do estado favorece os arranjos institucionais em que o estado nacional combine as funções de defesa territorial, garantia dos contratos, segurança pública e defesa da moeda, com sua especialização na formulação de políticas, no seu financiamento e regulação. Nesta configuração, as instituições públicas se afastam da provisão direta de bens e serviços, exceto para setores considerados estratégicos e não providos adequadamente em mercados (Brasil, 1995; Costa, 1999). Eventos recentes no setor saúde demonstram a implementação da agenda reformadora com a criação de novas agências regulatórias para a vigilância sanitária e saúde suplementar.

A regulação no setor saúde envolve estruturas tradicionais e inovações recentes. $O$ foco da regulação $e$ a agenda política setorial enfatizam as relações entre os níveis de governo municipal, estadual e federal; as relações entre governos e prestadores privados e semi-públicos contratados; $e$ as relações entre governo e agentes no mercado. O grande volume de dispositivos, instituições e departamentos e agências governamentais envolvidos com atividades de controle, avaliação, fiscalização, normatização torna o quadro regulatório bastante difuso. Desta forma, características nacionais como a existência de empresas estatais de capital misto, de entes públicos, estatais e não-estatais, regulados por contratos de gestão e de transferências de recursos da união para estados e municípios segundo padrões de comprometimento e desempenho de instâncias sub-nacionais, ampliam o foco da regulação, comumente voltada aos diferentes mercados, para o âmbito da administração pública. Perante este quadro complexo, o artigo define o foco da regulação mediante dois fundamentos: a contratualização e a vinculação a políticas.

A existência de contratos ou regulamentos definindo relações entre entes estatais pode ser reconhecida nos organismos de controle governamental sobre empresas como Petrobrás, Furnas, Nuclebrás, entre outras. No setor 
saúde, organismos colegiados, como a Comissão Intergestores Tripartite (formada por representantes dos executivos federal, estadual e municipal) regulam as transferências do SUS para entes subnacionais segundo compromissos estabelecidos pelas Normas Operacionais Básicas SUS 1993 e 1996. Por fim, a reforma do setor público em curso difundiu a contratualização entre entes públicos e originou contratos de gestão com agências executivas e organizações sociais. Desta forma, o âmbito da regulação se estende da auto-regulação e da regulação estatal sobre mercados, para a implementação de políticas voltadas à ampliação da qualidade e capacidade de instituições públicas.

$\mathrm{O}$ outro aspecto refere-se à própria articulação entre as diferentes atividades de controle sobre ações governamentais e de mercados. A regulação é tratada neste artigo como um conjunto de políticas formuladas para obter resultados superiores do ponto de vista social nas relações internas às estruturas de governo e em sua relação com agentes no mercado. Neste sentido, não são estudados os diversos organismos $e$ departamentos distribuídos pela burocracia pública com funções normativas desarticulados da agenda regulatória.

A administração pública brasileira foi estruturada como um mosaico de referências bem caracterizada como um modelo sincrético, em que coabitam padrões de clientelismo, corporativismo, insulamento burocrático $e$ universalismo de procedimentos (Nunes, 1997). Esta configuração repercute na diversidade de atividades regulatórias. São observados diversos organismos que se confundem com a própria burocracia pública $e$ apresentam caráter universalista e altamente normativo; são voltados ao controle de procedimentos e o conjunto de sua intervenção não assume as características dos modelos regulatórios orientados aos resultados. Apesar do caráter normativo e burocratizado, algumas das estruturas tradicionais, atualizadas ou não por legislação recente, influenciam a configuração final das funções regulatórias do estado. São exemplos os Tribunais de Contas de Estados (cujas decisões influenciam decisões do governo federal) e da União, o Sistema Nacional de Auditoria, o Ministério Público e as Secretarias de Controle Interno dos Ministérios. Estes organismos tomam decisões que afetam a formulação e implementação da política de saúde.

As relações entre níveis de governo, estabelecidas pela Constituição Federal e pelas Leis 8.080 e 8.142 , traduzem-se por um conjunto de portarias ministeriais, entre as quais se destaca a Norma Operacional Básica 01/1996, que consolida as comissões intergestores e o ranqueamento entre
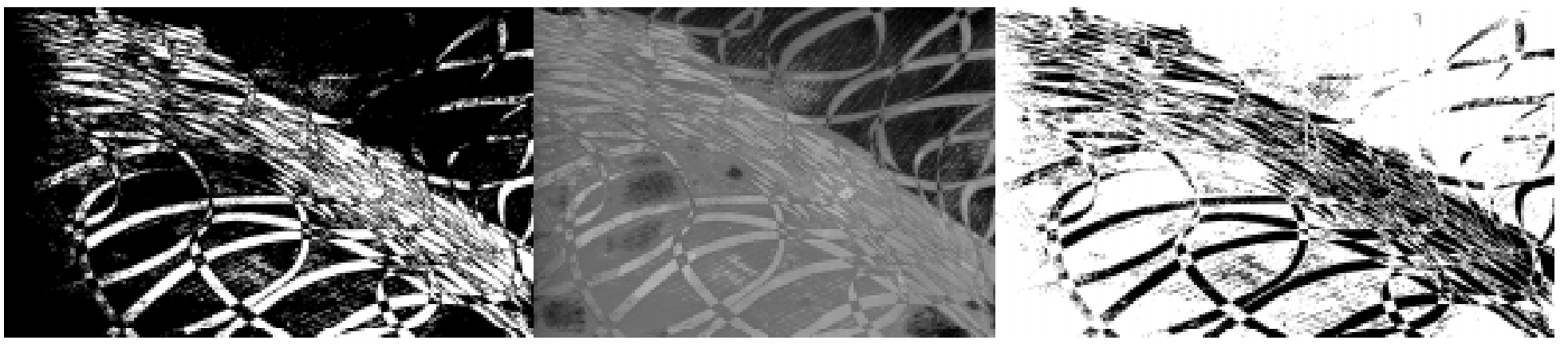
estados e municípios como forma de orientar transferências e investimentos do Sistema único de Saúde (SUS).

Ao longo da década de noventa, sob indução institucional combinada à ação de grupos ativos, foram também organizados conselhos multipartites (os conselhos de saúde) como entes voltados a compartilhar com o executivo funções de formulação e regulação na política de saúde. Associações civis, organizações não governamentais, grupos religiosos, clientelas organizadas, entre outros, convergiram para esses organismos, assim como entidades de defesa de direitos do consumidor. O mosaico descrito articula atividades regulatórias estatais com organismos societários $e$ agentes atuantes em diferentes mercados.

Com relação à micro-regulação, dois itens se destacam e apresentam convergência com a experiência internacional. Um deles diz respeito a inovações implementadas no setor público, consolidadas na figura dos contratos de gestão, que definem compromissos de organizações e nos programas de qualidade, que definem incentivos pagos aos profissionais de saúde. Em ambas as situações, a regulação implica o desdobramento de processos de trabalho de profissionais ou de organizações em unidades mensuráveis de avaliação de desempenho.

$\mathrm{O}$ outro item, embora não desenvolvido neste artigo, diz respeito à micro-regulação praticada no setor privado pelas empresas que absorvem estratégias de controle de custos e estruturação da oferta observadas no managed care norte-americano.

\section{Modelos regulatórios}

A moderna reforma regulatória começou nos Estados Unidos nos anos setenta, atingindo setores como telecomunicações e linhas aéreas $e$ expandiu-se por todo o mundo, incluindo os países do leste europeu e a antiga União Soviética. Na Grã-Bretanha, as indústrias dos anos oitenta representavam monopólios estatais. Ao longo da reforma regulatória, mercados foram liberalizados, indústrias reestruturadas e novos métodos $e$ instituições reguladoras foram criadas. Muitas iniciativas reduziram controles burocráticos e intervenção estatal. A desregulamentação radical fez parte das estratégias orientadas ao mercado, exaltando seu potencial auto-regulador.

No entanto, as reformas sucessoras buscaram redirecionar as funções de estado rumo a maior especialização na sua atuação. O conjunto de leis e normas dispersas pelo conjunto das instituições públicas foi progressivamente realocado para agências regulatórias, enquanto muitas atividades foram efetivamente delegadas ao mercado ou a estruturas intermediárias, na forma de uma auto-regulação vigiada. De modo geral, as instituições públicas preservaram o monopólio coercitivo $e$ as iniciativas políticas ao longo do processo reformador.

O modelo de regulação por agência tem sido difundido nas últimas décadas e as soluções britânicas de reforma de setores monopolísticos tornaram-se exemplares ${ }^{4}$.

Em que pesem tais inovações envolvendo reestruturação do aparelho de

\footnotetext{
${ }^{4}$ A reforma regulatória na Grã-Bretanha enfatizou a competição e o controle tarifário por meio de agências, adaptando cada setor à regulação de preços empregado para a telefonia, denominado $R P I-X$. O modelou buscou eficiência alocativa e produtiva $e$ controle sobre as diversas formas de captura pelos agentes econômicos. A firma submetida ao RPI - $X$ deveria assegurar que uma média ponderada de aumento de preços em um ano não excedesse o aumento percentual no índice de preços (Retail Prices Index), decrescido de um fator $X$ exógeno à firma entre os anos de revisão de preços (Armstrong et al., 1995)
} 
estado, muitas iniciativas de auto-regulação foram implementadas, o que tem preservado a polaridade entre soluções orientadas ao estado $e$ ao mercado. Igualmente, esquemas regulatórios intermediários buscam combinar tais orientações e criar soluções específicas para cada nação e ramo da indústria ou de serviços. Essas experiências situam-se como estratégias alternativas às soluções do tipo estatal universalista (sujeitas a problemas de captura e baixa flexibilidade) ou de desregulação, laissez-faire ou autoregulação (sujeitas às imperfeições de mercado). Um conjunto amplo de soluções intermediárias emerge na experiência internacional e nacional recente e influenciam, em diferentes graus, as decisões em curso no caso brasileiro, e no setor saúde em especial.

De modo geral, os esquemas regulatórios mais atraentes combinam estratégias diferenciadas $e$ individualizadas, que enfatizam a inclusão de grupos interessados no processo decisório, a indução a condutas responsáveis pelas empresas ou organizações semi-públicas e a maior especialização das agências estatais para focalizar a intervenção normativa stricto sensu.

Resumidamente, um mercado livre pode significar que a regulação privada organizada por cartéis impedirá a competição. Por outro lado, a regulação estatal indiscriminada pode ser facilmente contornada por realinhamentos de mercado. Evidências sugerem que uma boa política regulatória combina necessariamente aspectos da regulação estatal com a auto-regulação. A regulação é responsiva ao mercado na medida em que diferentes estruturas conduzam a graus e formas diferenciadas de regulação, envolvendo a delegação consciente de certas funções regulatórias (Ayres \& Braithwaite, 1992).

A estratégia das agências regulatórias deve considerar especificidades das empresas e dos ramos industriais e de serviços e promover um escalonamento do grau de intervenção estatal direta mediante punições. Uma estratégia baseada exclusivamente na persuasão ou na auto-regulação será explorada por agentes puramente orientados pela racionalidade econômica; uma estratégia baseada principalmente na punição enfraquece a iniciativa inovadora de agentes socialmente responsáveis.

$O$ modelo engenhoso e empiricamente testado de Ayres \& Braithwaite (1992) focaliza estes dois aspectos interligados: o escalonamento e a delegação. A implementação de graus variados de intervenção estatal configura uma pirâmide com uma base ampla centrada na persuasão (onde ocorre a maior parte dos eventos) e à medida que agentes exploram a delegação estatal (por captura, descumprimento de regras ou acordos), o regulador sobe na escala punitiva, desde advertências escritas, passando por penalidades civis, criminais, suspensão de licenciamento até sua própria cassação, no ápice onde ocorrem a minoria dos eventos. A política implica explicitar aos agentes a capacidade e a intenção do regulador em escalonar sua intervenção. Quanto ao grau de autonomia conferido aos mercados, a base da pirâmide envolve a auto-regulação e a escala cresce em intervenção estatal (por camadas e número cada vez menor de casos) desde a autoregulação controlada, regulação central com punições adaptadas ao caso $e$, por fim, a regulação central com aplicação de normas universais e penalidades fixas pelo regulador. 


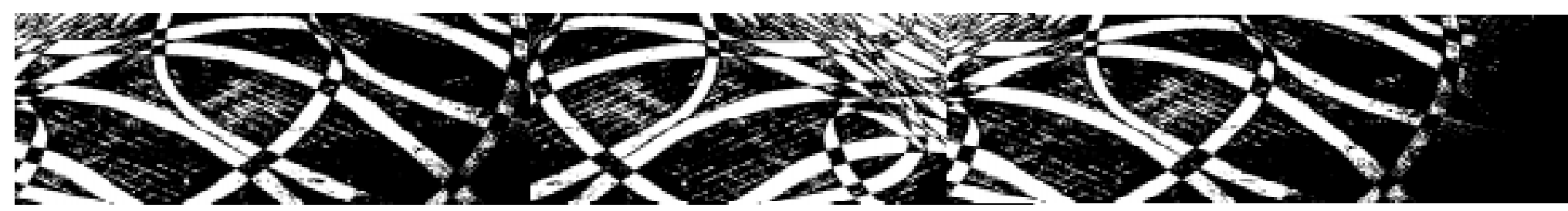

Com relação à delegação, Ayres \& Braithwaite (1992) apresentam uma estrutura organizacional capaz de implementar a noção de regulação responsiva. A principal estratégia é o tripartismo e visa fortalecer a cooperação no jogo regulatório e inibir a captura e a corrupção. $O$ tripartismo ou multipartismo implica delegar funções (empowering) a grupos de interesses públicos. São designados três pressupostos para assegurar eficiência à participação desses grupos: a) todos os seus membros devem ter acesso às mesmas informações disponíveis ao regulador; b) os grupos devem ter assento à mesa de negociações entre a empresa $e$ a agência regulatória; c) os grupos têm o mesmo poder de denúncia que o regulador.

Os problemas decorrentes da incorporação dos grupos públicos são contornáveis na implementação da política. A captura dos grupos pela empresa ou regulador é dificultada pela escala, na medida em que os grupos são competitivos entre si e não detêm monopólio de representação. $\mathrm{O}$ hiperativismo é parcialmente superado pela competição entre grupos e disseminação de informações aos liderados, embora problemas persistam com relação às associações que perdem adeptos por adotarem políticas cooperativas com governos e empresas.

Uma outra forma de delegação na política regulatória é a auto-regulação controlada, em que a negociação ocorre entre cada empresa e o estado em particular e a empresa é chamada a elaborar seu código de condutas para evitar que o estado proponha padrões exagerados ou tecnologicamente defasados. A vantagem refere-se aos casos de alta especialização das atividades das empresas. O código escrito deve estar adequado às estratégias do estado e uma vez rompido, o regulador sobe na escala punitiva estatal.

Outro modelo delegativo é o da intervenção parcial no ramo industrial, em que o estado regula apenas parte da indústria, esperando que as demais empresas do ramo acompanhem o padrão estabelecido. $O$ foco pode estar na empresa principal, para gerar um padrão de conduta dominante, ou nas mais fracas, para melhorar seu desempenho.

No caso do setor saúde no Brasil, o modelo acima se aplica com variações de tripartismo e de intervenção estatal escalonada segundo o setor (pirâmide de intervenção), embora inovações como a regulação parcial de empresas por ramo industrial (medicamentos, equipamentos médicos) ou auto-regulação controlada possam gerar cooperação e redução de custos de transação na política regulatória. O pressuposto básico do modelo está nas vantagens das condutas cooperativas, fundadas nas orientações sociotrópicas dos agentes, sobre as maximizadoras, fundadas na racionalidade econômica. 


\section{A Reforma do Estado no Brasil $e$ as novas agências regulatórias}

O curso da reforma do Estado no Brasil decorreu não apenas da interação com a agenda internacional, mas de fatores internos associados à crise fiscal. Como em diversos países, a reforma seguiu-se aos ajustes macroeconômicos, combinada à expectativa de ganhos de eficiência nas empresas públicas e de maior responsabilização nas relações entre governo $e$ sociedade.

De modo geral, a reforma decorre da crise do estado desenvolvimentista, do controle direto sobre a indústria e os serviços, e da falência do modelo organizacional da burocracia pública orientada pelos procedimentos. A reforma aponta para privatização de empresas públicas, estímulo à competitividade em setores monopolizados e, em termos de organização institucional, o estado busca reorientar sua estrutura no sentido de ampliar sua capacidade gerencial, desenvolver estruturas regulatórias e aumentar o grau de responsabilização. As mudanças propostas levam à redefinição da burocracia estatal, passando de um perfil organizacional para uma burocracia profissional assemelhada à norte-americana, nos moldes definidos por Silberman (1993).

$O$ redesenho das funções de estado e sua profissionalização influem nas políticas regulatórias, especialmente pela criação de agências.

A reforma é também difundida por agências internacionais que modulam suas soluções de acordo com os resultados obtidos em experiências modelares. O enfraquecimento de soluções centradas na redução absoluta do aparelho de estado levou à reorientação das proposições de agências influentes para estratégias de ampliação da capacidade institucional de interação do estado com mercados e de maior transparência nas decisões, enfatizando fatores como confiança e pactuação na relação entre agentes públicos e privados (Banco Mundial, 1997).

O Brasil interagiu mais diretamente com esta agenda após 1994, com o governo de Fernando Henrique Cardoso, e o desenho institucional foi expresso no Plano Diretor da Reforma do Aparelho do Estado (Brasil, 1995), do qual o fator dominante na implementação foram as privatizações de empresas estatais.

No debate interno fortaleceram-se idéias que associam o controle estatal direto de setores da economia com ineficiência; baixos investimentos em setores estratégicos (energético, siderúrgico, telefonia); e efeitos fiscais perversos. As empresas estatais e a burocracia pública foram consideradas capturadas pelos funcionários e os benefícios sociais da ação governamental como voltados ao incremento de welfare do pessoal interno.

A burocracia pública foi submetida a proposições de maior contratualização, mas a baixa confiança transmitida pelo governo federal aos agentes potenciais da mudança $e$ a subordinação das reformas a objetivos

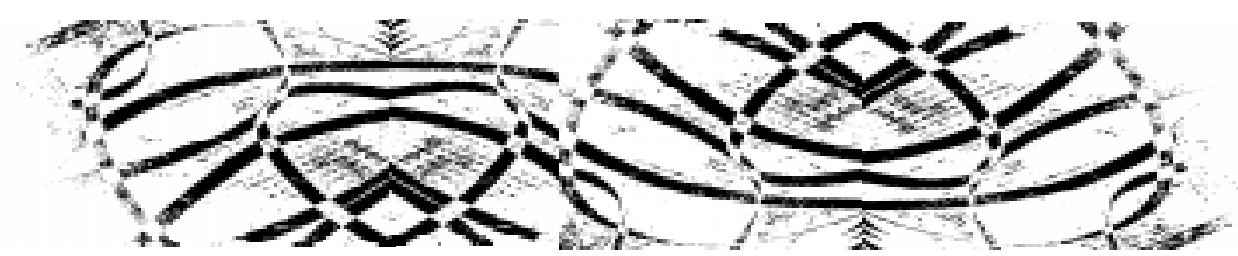

fevereiro, 2000 
fiscais ampliou a percepção de riscos de enfraquecimento definitivo da capacidade de estado. A convergência de padrões de burocracia organizacional e profissional exige abordagens mais complexas pelas próprias peculiaridades da formação do estado no Brasil.

A administração pública brasileira apresenta um modelo de sincretismo resultante de distintos padrões de trocas, resumidos por Nunes (1997) no clientelismo, no universalismo de procedimentos, no insulamento burocrático e no corporativismo. A reforma e os regimes regulatórios emergentes devem considerar as especificidades desta formação sincrética.

O Plano Diretor (Brasil, 1995) estabeleceu um desenho institucional coerente com processos em curso desde o início dos anos noventa, especialmente com o Programa Nacional de Desestatização, de 1991, e as próprias privatizações de empresas estatais da década de oitenta. Pelo desenho proposto, o Aparelho de Estado apresenta quatro setores diferenciados: a) o núcleo estratégico representa o governo propriamente dito e compreende os Poderes Executivo, Legislativo e Judiciário; b) as atividades exclusivas do estado, não delegáveis, envolvem regulação, segurança e arrecadação de impostos; c) os serviços não exclusivos, nas quais o estado pode atuar em cooperação com organizações públicas nãoestatais voltadas à promoção de justiça social ou preservação de atividades essenciais não providas adequadamente pelo mercado; $e$ d) produção de bens e serviços para o mercado, representando basicamente monopólios estatais submetidos a programas de privatização. As funções regulatórias se diferenciam quanto ao foco e às estruturas organizacionais de acordo com o setor abordado e sua posição no aparelho de estado.

A reforma no plano institucional implica em redefinir as formas de propriedade e a própria natureza jurídica das organizações públicas, o que traz conseqüências para as políticas regulatórias. Adota-se, além da propriedade estatal e privada, o conceito de propriedade pública não estatal materializada em organizações que não possuem proprietários e são orientadas ao interesse público. Tanto nas agências executivas (voltadas ao desempenho de atividades exclusivas e não delegáveis), como nas organizações sociais (para desenvolver atividades essenciais em cooperação com o Estado), as relações devem ser estabelecidas por contrato de gestão.

A privatização das empresas estatais tem sido o componente da reforma de implementação mais acelerada. Por outro lado, a reforma do serviço civil tem sido postergada $e$ as decisões governamentais nesta área têm sido subordinadas ao ajuste macro-econômico e à redução dos gastos públicos.

O modelo regulatório utilizado no Brasil segue a experiência internacional de intervenção governamental sobre os monopólios naturais $e$ de busca de eficiência alocativa e controle tarifário. No quadro a seguir, composto a partir da análise dos elementos principais da extensa legislação setorial, apresentamos as características das agências regulatórias criadas nos últimos anos nos setores elétrico, energético e de telecomunicações. Este modelo foi reproduzido na recente criação da Agência Nacional de Vigilância à Saúde e da Agência Nacional de Saúde Suplementar, vinculadas ao Ministério da Saúde. Segundo o Plano Diretor, estas agências configuram atividades essenciais e exclusivas de Estado. 
Comparativo da legislação regulatória, 1996-99, Brasil.

\begin{tabular}{|c|c|c|c|c|}
\hline & $\begin{array}{c}\text { Agência Nacional de } \\
\text { Energia Elétrica (ANEEL) }\end{array}$ & $\begin{array}{c}\text { Agência Nacional de } \\
\text { Telecomunicações (ANATEL) }\end{array}$ & $\begin{array}{c}\text { Agência Nacional de } \\
\text { Petróleo (ANP) }\end{array}$ & $\begin{array}{c}\text { Agência Nacional de } \\
\text { Vigilância Sanitária (ANVS) }\end{array}$ \\
\hline Lei & $\begin{array}{l}\text { lei } 9.427 \text {, de } 26 \text { de } \\
\text { dezembro de } 1996\end{array}$ & $\begin{array}{l}\text { lei } 9.472 \text {, de } 16 \text { de julho de } \\
1997\end{array}$ & $\begin{array}{l}\text { lei } 9.478 \text {, de } 06 \text { de agosto } \\
\text { de } 1997\end{array}$ & $\begin{array}{l}\text { lei } 9.782 \text {, de } 26 \text { de janeiro de } \\
1999\end{array}$ \\
\hline Regime * & $\begin{array}{l}\text { autarquia sob regime } \\
\text { especial }\end{array}$ & $\begin{array}{l}\text { autarquia sob rebime } \\
\text { especial }\end{array}$ & $\begin{array}{l}\text { autarquia sob regime } \\
\text { especial }\end{array}$ & autarquia sob regime especial \\
\hline Objetivos & $\begin{array}{l}\text { regular e fiscalizar o setor } \\
\text { de energia elétrica, } \\
\text { conforme políticas e } \\
\text { diretrizes do governo federal }\end{array}$ & $\begin{array}{l}\text { regular o setor e implementar } \\
\text { políticas nos termos da Lei } \\
\text { Geral de Telecomunicações }\end{array}$ & $\begin{array}{l}\text { regular, contratar e fiscalizar } \\
\text { as atividades econômicas } \\
\text { no setor eimplementar a } \\
\text { política nacional de petróleo } \\
\end{array}$ & $\begin{array}{l}\text { controle sanitário da produção, } \\
\text { comercialização e distribuição } \\
\text { de produtos e serviços sujeitos } \\
\text { à vigilância sanitária }\end{array}$ \\
\hline Diretoria & $\begin{array}{l}\text { diretor-geral e quatro } \\
\text { diretores, sendo um na } \\
\text { função de ouvidor }\end{array}$ & $\begin{array}{l}\text { conselho diretor com cinco } \\
\text { membros e um ouvidor, cujo } \\
\text { mandato é de } 2 \text { anos, } \\
\text { permitida uma recondução }\end{array}$ & $\begin{array}{l}\text { diretor-geral e quatro } \\
\text { diretores }\end{array}$ & $\begin{array}{l}\text { diretoria de até } 5 \text { membros, } \\
\text { com um diretor-presidente, um } \\
\text { ouvidor, um corregedor e um } \\
\text { procurador }\end{array}$ \\
\hline Grau de insulamento & $\begin{array}{l}\text { proibição de vínculo a } \\
\text { agentes ou órgãos } \\
\text { representativos do setor; } \\
\text { mandatos não coincidentes } \\
\text { de } 4 \text { anos; exoneração } \\
\text { imotivada de diretor só é } \\
\text { permitida nos quatro meses } \\
\text { iniciais do mandato; } \\
\text { quarentena de } 12 \text { meses }\end{array}$ & $\begin{array}{l}\text { mandato de } 5 \text { anos, vedada } \\
\text { a recondução; proibida } \\
\text { exoneração imotivada; } \\
\text { proibição de vínculo agentes } \\
\text { ou órgãos representativos do } \\
\text { setor e de exercício } \\
\text { profissional, salvo como } \\
\text { professor universitário; } \\
\text { quarentena de } 12 \text { meses }\end{array}$ & $\begin{array}{l}\text { proibição de vínculo a } \\
\text { agentes ou órgãos } \\
\text { representativos do setor } \\
\text { nos } 12 \text { meses anteriores; } \\
\text { mandato de } 4 \text { anos, não } \\
\text { coincidentes, permitida a } \\
\text { recondução; quarentena de } \\
12 \text { meses }\end{array}$ & $\begin{array}{l}\text { mandato de } 3 \text { anos, admitida } \\
\text { recondução; exoneração } \\
\text { imotivada apenas nos } 4 \text { meses } \\
\text { iniciais; proibição de vínculo a } \\
\text { agentes ou órgãos } \\
\text { representativos do setor, salvo } \\
\text { atividades em entidades } \\
\text { públicas de ensino e pesquisa; } \\
\text { quarentena de } 12 \text { meses }\end{array}$ \\
\hline Nomeação & $\begin{array}{l}\text { Presidência da República, } \\
\text { após aprovação pelo Senado } \\
\text { Federal }\end{array}$ & $\begin{array}{l}\text { Presidência da República, } \\
\text { após aprovação pelo Senado } \\
\text { Federal }\end{array}$ & $\begin{array}{l}\text { Presidência da República, } \\
\text { após aprovação pelo } \\
\text { Senado Federal }\end{array}$ & $\begin{array}{l}\text { Presidência da República, após } \\
\text { aprovação pelo Senado Federal }\end{array}$ \\
\hline Contrato de Gestão & $\operatorname{sim}$ & não & não & $\operatorname{sim}$ \\
\hline Receitas & $\begin{array}{l}\text { OGU; taxas de fiscalização } \\
\text { e outras; rendimentos de } \\
\text { operações financeiras; } \\
\text { recursos de convênios e } \\
\text { contratos celebrados; } \\
\text { doações e similares; venda } \\
\text { ou aluguel de imóveis e } \\
\text { móveis }\end{array}$ & $\begin{array}{l}\text { receitas do FISTEL; OGU; } \\
\text { rendimentos de operações } \\
\text { financeiras; multas e } \\
\text { indenizações, convênios, } \\
\text { acordos e contratos; } \\
\text { doações e similares; } \\
\text { prestação de serviços } \\
\text { técnicos }\end{array}$ & $\begin{array}{l}\text { OGU; participações por } \\
\text { implementação da } \\
\text { legislação; convênios, } \\
\text { acordos ou contratos; } \\
\text { doações e similares; taxas } \\
\text { e multas; vendas ou } \\
\text { locação de imóveis }\end{array}$ & $\begin{array}{l}\text { OGU; taxa de fiscalização } \\
\text { sanitária; retribuição por } \\
\text { serviços prestados; multas e } \\
\text { dívidas; convênios, contratos } \\
\text { ou acordos; doações e } \\
\text { similares; rendas de bens } \\
\text { móveis e imóveis }\end{array}$ \\
\hline
\end{tabular}

* A autarquia sob regime especial, parte da administração pública indireta, é caracterizada por independência administrativa, estabilidade de seus dirigentes, autonomia financeira e ausência e subordinação hierárquica.

FONTE: Leis Federais

A legislação regulatória converge em setores bem diferenciados. Primeiramente sua elaboração é recente, cobrindo o período de dezembro de 1996 a janeiro de 1999. Um aspecto relevante está na adoção do modelo autárquico especial, $e$ a autonomia daí decorrente, repercutindo no grau de insulamento dos diretores nomeados. Embora a duração dos mandatos varie, assim como a possibilidade de recondução, existem cláusulas de estabilidade nas funções, assim como regulamentos voltados a isolar as relações entre os diretores e agentes econômicos e atores políticos no setor. Este grau de insulamento mostra-se marcante quando cotejado com as funções bastante amplas desempenhadas por essas agências. Pelo caráter recente deste ordenamento, não existem estudos sobre o seu desempenho, nem sobre a implementação do contrato de gestão estabelecido para a ANEEL e ANVS. De modo geral, as agências possuem competências bastante amplas para intervir sobre mercado, fixar parâmetros, fiscalizar o comportamento dos agentes e estabelecer normas para maior 
competitividade nos setores em que a privatização foi mais acelerada, como nas telecomunicações e energia elétrica.

O caso brasileiro segue, no entanto, outros países ao priorizar a busca por recursos para investimentos em infraestrutura; isolar as empresas estatais do Tesouro Nacional; e arrecadar recursos volumosos para as contas governamentais. A eficiência econômica decorrente da mudança do controle acionário é esperada em função da orientação ao mercado das decisões internas das empresas. Embora a literatura aponte para casos em que estas expectativas não podem ser comprovadas, de modo geral a maior parte dos estudos realizados revelam ganhos de eficiência nas empresas desestatizadas. Por outro lado, embora reconhecidos, são menos evidentes os ganhos sociais advindos desses processos.

No Brasil são poucos os estudos empíricos avaliando a eficiência econômica e o incremento de welfare decorrente das privatizações, havendo maior dependência de dados obtidos por meio de relatórios de agências oficiais condutoras da privatização, como o BNDES, ou de consultorias econômico-financeiras. Segundo Pinheiro (1996), as privatizações da década de oitenta e do período 1991-94 promoveram ganhos em eficiência econômica, mas não se desconsidera a possibilidade das mudanças nas empresas se deverem a medidas paralelas de liberalização e desregulamentação. Além disso, assinala que os efeitos sociais da privatização não são bem medidos: de um lado a gerência privada tende a aumentar a eficiência empresarial e de outro, esta motivação pode levar a maior exploração dos consumidores, trabalhadores e meio ambiente.

Com relação à crise fiscal como fator motivante das privatizações, em 1995 a estimativa de necessidades de investimento governamental em infraestrutura era da ordem de US\$14,3 a 17, 9 bilhões ao ano e a disponibilidade orçamentária foi de US $\$ 7,3$ bilhões. Firmou-se a conviç̧ão de que somente o setor privado poderia levantar tais recursos. A motivação fiscal foi fator relevante para definição da estratégia de privatização no setor elétrico, o qual envolveu mais diretamente também os governos estaduais ${ }^{5}$. O processo em curso deverá refletir um balanço entre as falhas de mercado (tendência a concentração econômica) e as falhas de regulação ${ }^{6}$.

Os resultados gerais das privatizações em setores monopolísticos permitem dimensionar o impacto econômico provocado e a relevância da estrutura e dos mecanismos regulatórios em maturação. O Tesouro Nacional arrecadou com privatizações no Programa Nacional de Desestatização no período de 1991-97, o montante de US\$18 bilhões, havendo transferência de dívidas das empresas na ordem de US\$ 8,2 bilhões (Almeida, 1998).

\section{Dimensões dos sistemas público e privado de saúde no Brasil}

No caso brasileiro é marcante a interação entre os setores público e privado na conformação da atenção à saúde. No sistema público (Sistema único de Saúde - SUS), uma parcela significativa de serviços são comprados
${ }^{5} \mathrm{O}$ modelo adotado foi centrado em criar concorrência entre as empresas privadas na geração e distribuição de eletricidade, ao passo que as linhas de transmissão permaneceriam no setor público. As privatizações ocorreram em ambiente amigável ao investidor em razão das necessidades fiscais dos governos, que se refletiu no saneamento das empresas para a privatização $e$ alinhamento tarifário (Baer \& Macdonald, 1997).

\footnotetext{
${ }^{6}$ No antigo ambiente de regulação, os preços da eletricidade eram uniformes em todo o âmbito nacional e o governo garantia um retorno sobre os ativos de $10 \%$ a $12 \%$ ao ano. As empresas (todas públicas, naturalmente) que registrassem mais de $12 \%$ tinham de transferir o excesso de lucros para aquelas incapazes de auferir um retorno de pelo menos $10 \%$. Pela nova lei de regulação, todas as empresas são responsáveis por estabelecer suas próprias tarifas (com base em sua estrutura de custos), as quais então têm de ser aprovadas pela ANEEL (Baer \& Macdonald, 1997, p.32).
} 
junto a hospitais e clínicas privadas. Com relação ao setor privado, existe uma forte expansão de planos e seguros de saúde que envolvem subsídios indiretos.

A articulação entre os sistemas diversifica a política regulatória, que focaliza três itens principais: a) relacionados ao foco da regulação - sistema público (sobre transferências entre governos e compra de serviços aos prestadores privados) ou sistema privado (sobre regulação do mercado, como nos planos de saúde); b) relacionados ao desenho organizacional agências regulatórias especializadas, controle burocrático universal (tribunal de contas, ministério público, sistema nacional de auditoria) ou por conselhos muultipartites; c) relacionados ao instrumento - contratos de gestão, programas de incentivos, guias de decisão médica.

As políticas regulatórias objetivam o controle sobre os dois sistemas $e$ suas conexões. Grosso modo, a clientela divide-se em cerca de 41 milhões de usuários do setor privado e de 118 milhões usuários potenciais do SUS. Esta separação é meramente descritiva, na medida em que o SUS provê acesso universal e os beneficiários de planos e seguros de saúde recorrem, conforme o caso, às suas unidades. Os serviços contratados ao SUS, por sua vez, podem estabelecer relações contratuais com as empresas operadoras de planos e seguros de saúde.

As relações contratuais entre estes agentes, deles com governos e entre as diferentes esferas de governo são diversificadas, mas podem ser resumidas nas seguintes situações:

- entre o governo federal e estados e municípios, afora convênios e acordos caso a caso, as transferências e os compromissos são regulamentados pela legislação do SUS, atualizados e detalhados por normas operacionais e portarias; as principais são a Norma Operacional Básica SUS/ 1996 e a Instrução Normativa 01/1998 do Ministério da Saúde;

- entre os governos e prestadores as relações são também definidas nos termos da NOB 96 e da IN 98, entre os muitos regulamentos, seguindo padrões de credenciamento sem exclusividade ao SUS;

- entre os agentes privados e os consumidores a relação é contratual, porém a diversificação de condições contratuais foi reduzida após a recente regulação instituída pela Lei 9.656;

- entre os agentes privados e os profissionais contratados ou conveniados as relações são muito diferenciadas, mas os pagamentos envolvem de modo geral o cumprimento de tabelas e órgãos de representação dos médicos que interagem com as empresas e cooperativas no sentido de unificar valores por procedimentos.

As relações entre níveis de governo e destes com os prestadores privados são reguladas pelos parâmetros da NOB 96 e portarias vinculadas, assim como os pagamentos e transferências decorrem da aplicação de tabelas e são consolidadas em sistemas públicos de informação, como o SIA-SUS, SIH-SUS e diversas outras bases de dados nacionais. O sistema nacional de auditoria, estruturado por nível de governo, realiza a regulação tradicional das contas e produção de serviços e os conselhos de saúde desenvolvem os componentes políticos da regulação.

$\mathrm{O}$ dinamismo do sistema privado deve-se basicamente à medicina 
suplementar. A regulação estatal será discutida adiante em função da legislação recente. A micro-regulação implementada deve-se basicamente à aplicação pelas empresas de técnicas de managed care. Como pano de fundo para estas transformações está o impacto de custos de atenção e sua repercussão para os consumidores e para os próprios custos internos às empresas e cooperativas, entre outras modalidades ${ }^{7}$.

No Brasil os preços dos serviços de saúde subiram $110 \%$ desde agosto de 1994 (após o Plano Real) até agosto de 1997, para apenas 63\% de aumento do Índice de Preços ao Consumidor, IPC, medido pela FGV (crescimento real de $28,8 \%$ ).

Entre 1987 e 1992 o número de usuários da medicina supletiva cresceu a uma taxa média anual de $7,4 \%$ e a distribuição deste crescimento conforme setores é mostrada abaixo, onde se observa o dinamismo dos seguros-saúde.

Participação percentual no crescimento setorial, 1987-1992, por modalidade, Brasil.

\begin{tabular}{|l|l|}
\hline Seguro-saúde & $26 \%$ \\
\hline Cooperativas médicas & $18 \%$ \\
\hline Autogestão e planos administrados & $07 \%$ \\
\hline Medicina de grupo & $2,9 \%$ \\
\hline
\end{tabular}

FONTE: Conjuntura Econômica, maio/1998

Segundo dados publicados na revista Conjuntura Econômica, o setor que mais cresceu, o dos seguros-saúde, apresentou uma concentração para 1997 em três grandes empresas segundo prêmios auferidos, conforme dados de Demonstrações Contábeis Publicadas/FIP: Sul América (34,21\%); Bradesco (26,60\%); e Golden Cross (13,39\%). A cobertura aumentou 6,4\% entre 1992 (32 milhões de pessoas) e 1997 (41 milhões de pessoas). Em 1997 os planos coletivos respondiam por $75 \%$ da cobertura; com preço médio anual per capita de $\mathrm{R} \$ 462,5$ e custo de $\mathrm{R} \$ 367,50$, gerando 137 mil empregos diretos e 240 mil indiretos. O setor, que se expandiu com a medicina de grupo nos anos sessenta, cobra preços médios anuais de $\mathrm{R} \$ 306,00$ e apresenta os menores custos médicos anuais per capita do setor ( $R$ \$ 229,50 ). As seguradoras que surgiram mais tardiamente trabalharam com cálculos atuariais e reservas técnicas, tratando a doença como sinistro e o preço médio anual dos planos de seguros para 1997 foi de $R \$ 755,00$ para um custo médio de $\mathrm{R} \$ 566,00$. Segundo estas fontes, em dezembro de 1996 os 41.300 .000 de beneficiários/segurados em planos e seguros de saúde estavam distribuídos, sendo 10.530 .000 (25,5\%) em planos individuais e 30.770 .000 em planos coletivos (74,5\%).

Em comparação com o sistema SUS para 1997, que disponibilizou para 118,7 milhões o total de 6.992 hospitais (566 mil leitos e 70 mil médicos), o sistema privado apresentou vantagens no plano da oferta de serviços ao atender a 41 milhões de pessoas (34\% do SUS) ofertando 4.300 hospitais (62\% do SUS), 372 mil leitos (66\%) e 120 mil médicos (171\%). Estes dados devem ser, entretanto, correlacionados com sua distribuição regional, na medida em que tende a acompanhar a oferta de serviços em centros urbanos mais desenvolvidos, ao passo que o SUS possui uma distribuição bem mais
${ }^{7}$ Nos Estados Unidos, as tecnologias de managed care mostraram-se capazes, de início, de controlar custos médicos e hospitalares, embora os resultados quanto à preservação ou aprimoramento da qualidade dos serviços sejam menos evidentes (Robinson \& Steiner, 1998). 


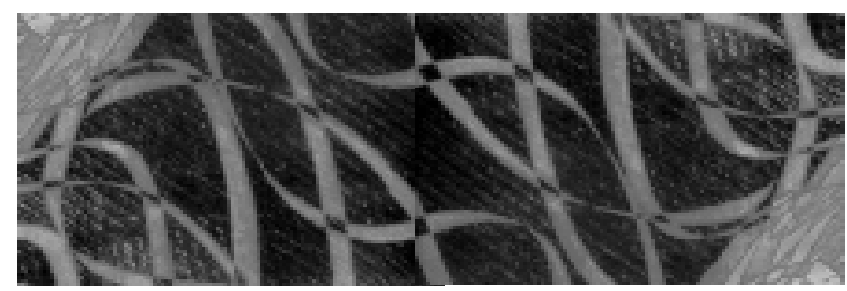

equitativa; fatores de custo e escala para desenvolver estruturas não disponíveis em regiões menos desenvolvidas tendem a diminuir a relação de médicos e leitos por segurado.

Com relação ao sistema público, a participação dos gastos nos três níveis de governo foi de 3,4\% do PIB em 1989; 2,3\% do PIB em 1993; voltando a subir para 3,5\% do PIB em 1997. Observado isoladamente, o gasto do governo federal com Saúde sofreu uma queda, indo de 2,7\% do PIB, ao final da década de oitenta, para 2,3\% do PIB em 1997, mesmo com a receita da CPMF. Segundo o IPEA, o Gasto Social Federal com Saúde no Brasil, em 1996, em relação ao gasto federal total (fiscal e seguridade social), foi de $4,1 \%$.

A transferência de recursos federais destinados à assistência à saúde para estados e municípios define a dimensão do esforço regulatório. Para 1998, segundo cálculos efetuados a partir de dados do Datasus, $62,19 \%$ dos recursos destinados ao pagamento da produção ambulatorial e hospitalar foram destinados aos governos estaduais para remuneração de sua rede própria ou transferência aos seus municípios não dotados de autonomia plena. Os restantes 37,81 \% foram remetidos diretamente aos municípios então habilitados em gestão plena do sistema nos termos da NOB 96.

O esforço regulatório do conjunto do sistema SUS pode ser avaliado também pela dimensão das transferências a prestadores privados. Ainda segundo estes cálculos, 46,52\% dos recursos foram destinados a pagar despesas com hospitais e ambulatórios privados (com ou sem fins lucrativos) contratados ao SUS. Na realidade este percentual é maior em função da parcela de serviços universitários não estatais remunerados pelo sistema.

Os dados são resumidos no quadro abaixo e mostram a dimensão dos modelos regulatórios que envolvem tanto relações entre governos, como as estabelecidas com os diferentes mercados. A diversidade de controles, normas e organismos envolvidos, distribuídos por níveis de governo $e$ organismos reguladores comuns, permite descrever para o sistema público um quadro regulatório em que cohabitam principalmente os modelos estatal normativo e tripartismo, como discutido mais adiante.

Transferências de recursos federais segundo gestão e tipo de prestador, SUS, em reais correntes, 1998

\begin{tabular}{|c|c|c|c|c|}
\hline \multirow{3}{*}{ Gestão } & Estadual & \multicolumn{2}{|c|}{ Municipal } & Total \\
\hline & 4.897.626.371,88 & \multicolumn{2}{|c|}{$2.977 .904 .950,11$} & $7.875 .531 .321,99$ \\
\hline & $62,19 \%$ & \multicolumn{2}{|c|}{$37,81 \%$} & $100 \%$ \\
\hline \multirow{3}{*}{ Prestador } & Público & Privado & Universitário & Total \\
\hline & $2.710 .124 .483,66$ & 3.663.334.651,84 & $1.502 .072 .186,49$ & $7.875 .531 .321,99$ \\
\hline & $34,41 \%$ & $46,52 \%$ & $19,07 \%$ & $100 \%$ \\
\hline
\end{tabular}

FONTE: Datasus/MS 
Os números apresentados pelo sistema público são bastante significativos, especialmente se levarmos em conta que a oferta é bastante diversificada $e$ envolve itens de alto custo e alta complexidade, como transplante de órgãos, quimioterapia, hemodiálise, cirurgia cardiovascular, entre outros. A compra de serviços privados, ambulatoriais e hospitalares, é significativa, tornando a regulação sobre desembolsos e qualidade dos serviços item altamente relevante no cotidiano de ministros e secretários de saúde.

\section{A regulação dos planos e seguros de saúde no Brasil: universalismo normativo e tripartismo}

O crescimento da atenção supletiva no Brasil exacerbou a assimetria entre as empresas que atuam no setor e os consumidores, especialmente quanto a regras de acesso, garantias, percepção de direitos e transferência de custos. Modalidades minoritárias, como nos planos de autogestão, voltadas para clientelas organizadas, mais comuns entre funcionários públicos $e$ empregados de empresas estatais, mostram condições mais favoráveis de barganha dos associados com as operadoras. Por outro lado, os empregadores de modo geral possuem menor domínio de informações $e$ experiência em negociar diretamente com as operadoras que vendem planos coletivos. Os consumidores individuais, por sua vez, tradicionalmente dispõem de menores recursos de ação coletiva para assegurar melhores preços e serviços. A percepção de assimetria na relação dos agentes econômicos entre si e com consumidores gerou pressão política $e$ intervenção do governo federal, no sentido de regular o setor em termos nacionais.

Pela complexidade do setor, as estratégias regulatórias implementadas e em formulação seguem as características básicas do modelo proposto por Ayres e Braithwaite (1992). O universalismo normativo guarda consonância com as atribuições da recém-criada Agência Nacional de Vigilância Sanitária, vinculada ao Ministério da Saúde, na qual a aplicação de multas e o acompanhamento da produção industrial e de serviços ocupa o centro da atuação. O tripartismo manifesta-se nos organismos colegiados com funções regulatórias, que incorporam representantes de empresas, profissionais de saúde e usuários, como a câmara de saúde suplementar. A formação de agência regulatória segue a tendência reformadora em curso no país. O escalonamento da intervenção estatal e a seletividade na atividade regulatória dependem de interações repetidas e prolongadas entre governo, grupos públicos e empresas em um novo ambiente regulador.

A nova legislação federal ${ }^{8}$ para o mercado de planos e seguros de saúde no Brasil concentrou-se em dois pontos básicos: padronizar parte dos serviços oferecidos e montar um sistema regulatório eficiente. Medidas adicionais, como o controle da seleção de risco praticado por diversas operadoras e a exigência de garantias financeiras, seguindo padrões da SUSEP, na comercialização dos planos buscam melhorar a posição dos consumidores no mercado.

Em linhas gerais, a nova legislação: abre o setor a grupos estrangeiros; cria um pacote mínimo de assistência à saúde; controla a seleção de risco

\footnotetext{
${ }^{8}$ A Lei que dispõe sobre os planos e seguros de assistência à saúde é a de $n^{\circ} 9.656$ de 3 de junho de 1998, alterada por dezenas de sucessivas Medidas Provisórias. Após sua publicação, o conflito de interesses no setor envolvendo representantes governamentais, das diversas organizações privadas e de entidades médicas, resultou em sucessivos adiamentos no prazos de execução da lei e a revisão de alguns itens.
} 
pelas operadoras; define garantias securitárias aos associados; cria organismos colegiados como a Câmara de Saúde Suplementar com representantes governamentais, do Conselho Nacional de Saúde, do CONASEMS, do CONASS, de entidades de defesa de consumidores, de clientelas organizadas, de entidades representantes das empresas que atuam no setor e de representantes dos médicos e odontólogos; define o ressarcimento pelas operadoras de serviços prestados a seus consumidores em unidades do sus.

A disputa sobre as regras de atuação e configuração regulatória final mostra forte resistência da parte dos ofertantes de planos e seguros de saúde. A Confederação Nacional de Saúde, que representa a medicina de grupo, e a Confederação Nacional do Comércio, representante das seguradoras, argüíram no Superior Tribunal Federal duas ações de inconstitucionalidade sobre a Lei 9.656.

Por sua vez, o governo federal optou por concentrar a atividade regulatória sobre o setor pela criação recente da Agência Nacional de Saúde Suplementar, nos moldes das demais agências.

O controle de custos e a impossibilidade de plena transferência aos consumidores em função da ação de órgãos governamentais (CADE federal, PROCON estaduais) e da competição em mercado, levam as empresas a buscar mecanismos internos de controle do trabalho médico e encontram forte oposição de entidades médicas à propalada "invasão do managed care norte-americano". O Conselho Federal de Medicina (CFM), representado na Câmara de Saúde Suplementar, desenvolve forte atividade no sentido de maior controle governamental sobre o sistema e resistência a perdas dos médicos no ajuste financeiro das empresas. Os limites entre a defesa do predomínio do sistema público combinado à resistência com relação a possíveis perdas de médicos contratados ou conveniados a operadoras ou cooperativas leva o próprio CFM a ter reservas com relação ao ressarcimento ao SUS pelo atendimento de segurados em sua rede, como previsto pela Lei 9.656 .

A intensa atividade de grupos de interesses médicos, de clientelas organizadas e de operadoras de planos e seguros torna complexo o jogo regulatório. Com relação ao setor privado, diversas associações são ativas na esfera política e a defesa de interesses compõe um mosaico em função da própria clientela atendida. A competição no mercado em função dos produtos oferecidos se reproduz no plano político e a distribuição de perdas é desigual. O perfil da atividade política está diretamente ligado ao segmento representado e à percepção de perdas frente à nova legislação.

\section{A regulação das relações entre esferas de governo}

De modo geral, as relações entre esferas de governo não costumam ser tratadas como item da economia da regulação. No entanto, as relações peculiares entre os níveis de governo no âmbito do SUS no Brasil e os diversos organismos pluripartites que regulam as transferências $e$ atribuições permitem que se observem políticas reguladoras que permeiam o processo de descentralização da política de Saúde. As relações do governo 
federal com os governos estaduais e municipais e entre o sus e os prestadores privados são reguladas por diferentes organismos $e$ departamentos, porém três instâncias regulatórias apresentam-se como as mais relevantes e demonstram modelos diferenciados de controle dos serviços e ação do sistema público: o Sistema Nacional de Auditoria, as Comissões Intergestores e os Conselhos de Saúde.

O Sistema Nacional de Auditoria (SNA) foi instituído pela Lei 8.689 de 27 de julho de 1993 e regulamentado pelo decreto 1.651 de 28 de setembro de 1995. O processo de montagem do sistema foi conflituoso, pois gestores municipais contestaram uma possível perda de autonomia em suas atribuições. O sistema atua em nível federal, estadual e municipal. Tem autoridade pública e audita o sistema quanto aos repasses: do Fundo Nacional de Saúde aos fundos estaduais e municipais de saúde nos termos do decreto 1.232/94; por serviços produzidos na forma de pagamento direto aos prestadores estatais ou privados, contratados e conveniados contra apresentação de faturas referentes aos serviços realizados e mediante prévia autorização do gestor; de programas federais de assistência social.

O SNA procura associar as funções típicas de auditagem com avaliação da qualidade de gestão, mediante acompanhamento dos seguintes indicadores: taxa de internações desnecessárias; taxa de desperdícios financeiros na Unidade Prestadora de Serviço (UPS); índice de custos em serviços auxiliares de diagnose e terapia (SADT); índice de ações e programas preventivos realizados; fluxo de informações no SIA e SIH-SUS.

O modelo regulatório tem caráter universalista e burocrático, embora o escalonamento nas punições vise aprimorar a qualidade dos serviços. Esta é auferida pelo adequado cumprimento de normas e bom desempenho nos indicadores citados. A vulnerabilidade à captura decorre da relação direta entre auditor e empresa ou gestor. O controle sobre a captura do regulador é efetuado pela disseminação de informações, na medida em que o SUS possui alta visibilidade dos dados de produção de serviços $e$ de pagamentos efetuados e os gestores também estabelecem relações diretas com os prestadores.

As comissões intergestores são colegiados criados pela Norma Operacional Básica SUS-1993 e mantidas por portarias ministeriais posteriores. São órgãos colegiados compostos por gestores municipais $e$ estaduais, nas bipartites regionais $e$ estaduais, $e$ por representantes do Ministério da Saúde e dos conselhos nacionais de secretários municipais e estaduais de saúde na tripartite, de caráter nacional. Existem em todos os estados e no nível federal. São organismos políticos de caráter paritário, o que induz à pactuação de interesses. A captura ou a obstrução acompanha a formação de coalizões políticopartidárias ou de caráter setorial. O foco de sua intervenção está na gestão dos recursos do SUS e suas atribuições competem com a do SNA. O procedimento é menos normativo, em termos comparados, $e$ as decisões tendem a se adaptar aos casos. A regulação resulta basicamente da competição entre os gestores pelos recursos públicos disponíveis e da aplicação de parâmetros nacionais de repartição de recursos orçamentários. 
Os conselhos de saúde previstos pela Constituição de 1988 e regulamentados pela Lei 8.142 de 1990 são compostos por representantes governamentais, de profissionais de saúde e de entidades comunitárias. Constituídos ao longo da década de noventa, o escopo de sua intervenção dá-se por nível de governo. Assim, existe o Conselho Nacional de Saúde e os Conselhos Estaduais e Municipais. Segundo a regulamentação em vigor, possuem caráter deliberativo para questões ligadas ao setor saúde e relacionadas a cada executivo governamental. A dinâmica desses conselhos é bastante associada à agenda política local e seu papel na regulação é bastante variável. Nos locais, onde o organismo funciona como um efetivo colegiado político, o papel regulatório envolve desde o estabelecimento de normas e prioridades para a política de saúde, mediante conferências anuais e o estabelecimento de um plano de intervenção, até funções de ouvidoria pública e fiscalização da qualidade dos serviços prestados pelo sistema público. Os conselhos de saúde estão consolidados no país e seu funcionamento é um dos requisitos para o acesso a recursos da união para estados e municípios. O Conselho Nacional de Saúde (CNS) é o mais antigo, $e$ sua fundação precede a legislação setorial recente e os conselhos estaduais estão implantados em todas as unidades federadas. Quanto aos municípios, o número preciso não está disponível, porém pode-se afirmar que estão implantados em pelo menos 5.274 dos 5.506 municípios brasileiros, correspondendo àqueles habilitados pela Norma Operacional Básica - 1996, que regula as transferências de recursos do SUS, segundo dados do Ministério da Saúde para julho de 1997.

Com relação à configuração regulatória atual do setor saúde, o CNS possui caráter especialmente relevante. A lei 8.142, de 1990, estabeleceu que os conselhos e as conferências de saúde deveriam se constituir como organismos de convergência dos interesses diversos estruturados por governos, profissionais e usuários e desenvolver funções de formulação de políticas e regulação em sentido amplo. O CNS possui existência legal desde 1937 como organismo colegiado de caráter consultivo e exercendo funções normativas por sistema de pareceres técnicos. Em 1990, já sob a nova legislação, foi recriado pelo Decreto 99.438 , com as funções e composição atualmente observadas, devendo deliberar emitindo resoluções ao Ministério da Saúde. Ao longo da década o cumprimento de suas resoluções esteve bastante associado às coalizões políticas formadas, e o organismo representa importante formador da agenda setorial. O CNS é formado por 32 conselheiros titulares, representando instituições governamentais, prestadores de serviços privados de saúde, profissionais de saúde e usuários.

A composição diversificada $e$ as atribuições conferidas em Lei conferem ao CNS importante papel na política regulatória. O modelo é típico do tripartismo e a regulação é flexível, orientada a resultados, adaptada aos casos, centrada no cumprimento de normas universais do sistema, porém sem o caráter processual do sistema de auditoria. Com relação aos problemas de captura, a composição dos membros funciona como importante barreira e o problema de assegurar os benefícios da cooperação estão no ativismo político, pelo qual algumas entidades preservam sua identidade por meio da denúncia sobre decisões governamentais. A atuação 
cooperativa dos representantes governamentais, por sua vez, influencia o benefício de resultados pactuados.

Com relação aos métodos e instrumentos no jogo regulatório das relações entre esferas de governo, observa-se a competição entre parametrização burocrática, em que o controle da captura decorre do seguimento de normas e acompanhamento de indicadores, e a pactuação política em organismos próprios, decorrentes da disseminação de informação, da contestabilidade dos representantes e da disputa entre os agentes e grupos organizados. A participação de grupos de interesses públicos serve também como mecanismo de redução da captura. Por outro lado, o povoamento das instâncias decisórias por estes grupos e a politização de suas relações geram problemas de baixa cooperação pela dificuldade de representantes de diversas organizações explicarem a seus associados motivos de adesão a políticas governamentais.

No setor saúde, os contratos de gestão são freqüentemente considerados como meios para regular a concessão de autonomia do executivo para os hospitais. A autonomia pode ser ampla como na forma de organização social adotada por leis estaduais como em São Paulo e Bahia, ou mais restrita, quando os contratos servem da parâmetro para as relações entre núcleo central de governo e unidades públicas vinculadas.

Apesar da adesão de especialistas e gestores ao modelo de gestão pública hospitalar centrado na autonomia gerencial e na contratualização de metas, procedimentos e indicadores, pesquisa realizada nos municípios do Rio de Janeiro e São Paulo ${ }^{9}$ mostram que os hospitais públicos não introduziram esses mecanismos, apesar da adesão de seus dirigentes ao modelo. Por sua vez, o contrato de gestão tem sido utilizado para regular as relações entre o governo estadual de São Paulo e as unidades hospitalares recém-construídas e gerenciadas em regime de organização social. Outros estados brasileiros, como a Bahia, possuem legislação similar disciplinando o modelo gerencial das novas unidades hospitalares.

Por fim, refletindo a diversidade de estratégias regulatórias e a própria competição entre modelos, o Ministério da Saúde implementou um programa de acreditação hospitalar que promove uma classificação dos hospitais brasileiros segundo sua performance. O modelo de acreditação hospitalar associa avaliação de processos com certificação de qualidade dos serviços. Os parâmetros estão fixados no Manual de Acreditação Hospitalar e o programa resultou de parceria do Ministério da Saúde com associações médicas, institutos de pesquisa e associações hospitalares. Em dezembro de 1998, o Ministério da Saúde assinou protocolo de intenções com as entidades fundadoras da ONA. Pela composição e atribuição da organização criada, observa-se uma forma de auto-regulação induzida ou contratada em função da presença de representantes governamentais e do mercado. As entidades fundadoras envolvem grupos de prestadores de serviços ao SUS, operadoras de planos e seguros de saúde, cooperativas médicas, além do Conselho Nacional dos Secretários de Saúde (Conass) e do Conselho Nacional dos Secretários Municipais de Saúde (Conasems).

As entidades fundadoras são associações de direito privado, porém o status público é conferido não apenas pela indução do MS, mas pela
${ }^{9}$ Pesquisa em curso

"Reforma do Estado e o Setor Saúde". NEPP/ UNICAMP, ENSP/

FIOCRUZ U UFPE financiada pelo CNPq/ CAPES/FINEP/MARE. 
presença do Conasems e Conass representando autoridades sanitárias. O sistema de acreditação em desenvolvimento representa mais uma estrutura micro-regulatória da assistência à saúde e deve se articular aos padrões de macro-regulação observados para o setor público (que segue a estrutura da das Leis 8.080 e 8.142 ) e setor privado (que segue a estrutura da Lei 9.656).

A contratualização das relações internas ao sistema público no Brasil apresenta focos distintos e complementares. Os três níveis de governo têm regulado a compra de serviços aos prestadores privados mediante Portarias do Ministério da Saúde, dentre as quais destaca-se a NOB-96. Nestas condições, o foco da regulação direciona-se ao volume de serviços produzidos e ao cumprimento

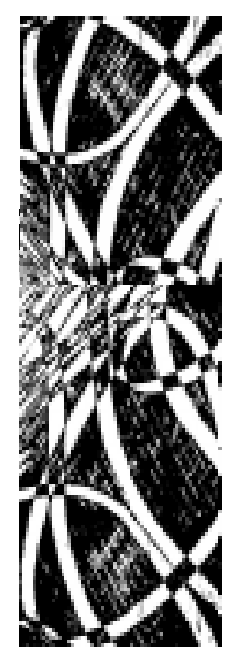
das normas de pagamento vigentes, apesar da ênfase em itens de qualidade na cobertura das ações e dos serviços ofertados. Os contratos de gestão elaborados para o sistema público buscam associar mais objetivamente a qualidade da atenção, satisfação do usuário, cesta de serviços ofertados pelas unidades reguladas e introduzem incentivos a boa performance institucional. Com relação às técnicas de managed care, elas se traduzem no sistema público pelas estratégias de ampliação da capacidade resolutiva das unidades ambulatoriais voltadas ao primeiro atendimento aos usuários, como nos programas de saúde da família. Diversos componentes da atenção gerenciada, como a resolutividade das unidades locais, o referenciamente justificado aos níveis de maior complexidade e o seguimento de guidelines clínicos são amplamente utilizados no caso brasileiro. A micro-regulação no setor público tende claramente a associar estas técnicas aos contratos de gestão que estipulam a maior autonomia organizacional.

\section{Síntese sobre modelos regulatórios do setor saúde no Brasil}

Ao longo do artigo destacou-se uma abordagem da teoria regulatória, apresentando-se um conjunto de iniciativas desenvolvidas no Brasil para o setor saúde ao longo dos anos noventa, inscritas na formação de sistemas regulatórios de caráter nacional. Como ressaltado, a multiplicação de exemplos e a superposição de funções de agência com os procedimentos cotidianos de departamentos de diversos ministérios no governo federal promove alta superposição de atividades de fiscalização, penalização, avaliação, defesa de direitos e inúmeras práticas passíveis de enquadramento em uma política governamental de regulação setorial. Além disso, os poderes legislativo e judiciário, por meio de suas instituições, expressam a coerção legítima de Estado.

No trabalho, a regulação foi tratada na forma de uma política governamental de caráter nacional que interage com agentes privados $e$ públicos. A ênfase no caráter político da regulação implica dois aspectos. $\mathrm{O}$ primeiro trata do reconhecimento de um corpo estatal regulatório mais amplo do que ações localizadas em determinada política setorial. O segundo destaca a política implementada como componente das reformas 
regulatórias contemporâneas.

O quadro a seguir seleciona e correlaciona modelos regulatórios e algumas políticas e organismos ativos, focalizando as relações do governo federal com organismos privados e com governos estaduais e municipais. Combina iniciativas desenvolvidas ao longo da década de noventa com um modelo de regulação flexível voltada aos ganhos da cooperação sem perda de autoridade normativa estatal. As lacunas são ocupadas na parte superior pela descrição do organismo principalmente vinculado ao processo regulatório e, na parte inferior, pelos principais instrumentos e estratégias utilizados.

Quadro resumo da política regulatória no setor saúde no Brasil: aspectos relevantes

\begin{tabular}{|c|c|c|c|c|c|}
\hline $\begin{array}{l}\text { Modelo } \\
\text { regulatório }\end{array}$ & $\begin{array}{l}\text { Planos, Seguros, } \\
\text { Empresas de Saúde }\end{array}$ & $\begin{array}{c}\text { Indústria } \\
\text { farmacêutica e de } \\
\text { alimentos }\end{array}$ & $\begin{array}{c}\text { Prestadores } \\
\text { privados do SUS }\end{array}$ & Médicos & $\begin{array}{l}\text { Transferências } \\
\text { para estados e } \\
\text { municípios }\end{array}$ \\
\hline \multirow{2}{*}{$\begin{array}{l}\text { Estado normativo } \\
\text { e/ou escalonado }\end{array}$} & $\begin{array}{l}\text { Departamento de Saúde } \\
\text { Suplementar/MS; } \\
\text { Superintendência de } \\
\text { Seguros Privados } \\
\text { (SUSEP); nova ANSS } \\
\end{array}$ & $\begin{array}{c}\text { Agência Nacional de } \\
\text { Vigilância Sanitária } \\
\text { (ANVS) }\end{array}$ & $\begin{array}{c}\text { Sistema Nacional de } \\
\text { Auditoria (SNA) }\end{array}$ & & $\begin{array}{r}\text { Sistema Nacional } \\
\text { de Auditoria (SNA) }\end{array}$ \\
\hline & $\begin{array}{c}\text { Autorização para } \\
\text { funcionamento; } \\
\text { intervenção; perda de } \\
\text { registro }\end{array}$ & $\begin{array}{c}\text { Notificações, multas, } \\
\text { suspensão, perda de } \\
\text { licença e processos } \\
\text { judiciais }\end{array}$ & $\begin{array}{c}\text { Auditoria; processos } \\
\text { judiciais }\end{array}$ & & $\begin{array}{c}\text { Auditoria; } \\
\text { processos judiciais }\end{array}$ \\
\hline \multirow[t]{2}{*}{ Tripartismo } & $\begin{array}{l}\text { Câmara de Saúde } \\
\text { Suplementar }\end{array}$ & & $\begin{array}{c}\text { Conselho Nacional } \\
\text { de Saúde (CNS); } \\
\text { Comissão } \\
\text { Intergestores } \\
\text { Tripartirte (CIT) }\end{array}$ & & $\begin{array}{c}\text { Conselho Nacional } \\
\text { de Saúde (CNS); } \\
\text { Comissão } \\
\text { Intergestores } \\
\text { Tripartirte (CIT) }\end{array}$ \\
\hline & Resoluções & & $\begin{array}{l}\text { Resoluções; } \\
\text { inspeções }\end{array}$ & & Resoluções \\
\hline \multirow{2}{*}{$\begin{array}{l}\text { Auto-regulação } \\
\text { contratada }\end{array}$} & & & $\begin{array}{c}\text { Organização } \\
\text { Nacional de } \\
\text { Acreditação (ONA) }\end{array}$ & & \\
\hline & & & $\begin{array}{l}\text { Certificados de } \\
\text { Qualidade }\end{array}$ & & \\
\hline Auto-regulação & & & & $\begin{array}{c}\text { Conselho } \\
\text { Federal de } \\
\text { Medicina (CFM) } \\
\\
\text { Processos } \\
\text { éticos; } \\
\text { advertência e } \\
\text { cassação de } \\
\text { registro } \\
\text { profissional }\end{array}$ & \\
\hline
\end{tabular}

Os padrões de análise de Ayres \& Braithwaite (1992), utilizados para analisar a política regulatória do setor saúde, representam uma aproximação inicial. Do modelo original unificou-se a pirâmide de controle escalonado. Nesta, o regulador parte de uma base inicial de aplicação tolerante das leis e normas, permitindo uma adaptação da empresa e recorre à aplicação stricto 
sensu das penalidades em casos de captura ou descumprimento de compromissos assumidos, correspondente ao pico da pirâmide na qual se situam poucos casos. No caso brasileiro, o escalonamento freqüentemente é previsto nas normas de fiscalização, embora no modelo analítico referido o escalonamento na aplicação de penas dependa de elevada autonomia do regulador e conseqüente vulnerabilidade à captura pela empresa.

A regulação estatal normativa é aplicada às indústrias e aos serviços sujeitos à fiscalização sanitária e o escopo da intervenção é bastante amplo. A atuação das industrias farmacêutica e de alimentos e todo o setor de comercialização destes produtos são alvos privilegiados da política regulatória. O governo federal criou a ANVS nos moldes utilizados para as agências regulatórias de setores recentemente privatizados com características de monopólios naturais. O regime de autarquia especial confere maior autonomia orçamentária e o mandato e estabilidade de sua diretoria visam assegurar controle da captura de seus membros. Com o desenvolvimento da agência e melhor conhecimento entre os agentes, é possível e desejável que altere o regime normativo para formas de autoregulação contratada, em que o regulador permite que as indústrias redijam seus códigos de procedimentos ou combine sua intervenção com a regulação seletiva, em que o foco se dá no controle de uma ou mais indústrias na expectativa de que o padrão atingido seja seguido pelas demais, reduzindo os custos da regulação. O modelo foi recentemente adotado para a Agência Nacional de Saúde Suplementar (ANSS).

O modelo estatal normativo é também observado na política regulatória das relações estabelecidas pelo SUS com os prestadores privados e nas próprias transferências entre os níveis de governo. Com relação aos prestadores contratados ao SUS, o Sistema Nacional de Auditoria, formado como organismo regulador federal, possui componentes nos estados $e$ municípios. Ao longo da implementação deste modelo, observou-se forte competição dos níveis sub-nacionais no sentido de preservar sua autoridade sobre os contratos firmados. A atuação é pautada pela auditagem de procedimentos com relação ao atendimento de normas e o sistema busca ampliar o foco da regulação para o acompanhamento de indicadores de desempenho das unidades. A mesma lógica é utilizada para auditar as transferências federais para estados e municípios e, neste caso, suas funções se superpõem com as da secretaria de controle interno do ministério da saúde. Com relação a tendências para este modelo pode-se esperar um predomínio da atuação das comissões intergestores, mais flexível e aderida à agenda política setorial e pactuada, na regulação das relações internas ao sus.

O setor de saúde suplementar está sujeito a dois macro-regimes regulatórios (estatal normativo e tripartismo), em que o padrão normativo foi exercido inicialmente de forma competitiva pelo Ministério da Saúde, por meio do Departamento de Saúde Suplementar, e Ministério da Fazenda, pela SUSEP. No caso, as funções dos dois organismos foram transferidas para a agência reguladora na órbita do Ministerio da Saúde. A transição esperada no caso, em função da alta pulverização do mercado de planos e seguros de saúde, está na transferência de elementos da política regulatória do padrão 
normativo para o tripartite.

O tripartismo aparece como solução única ou combinada para três segmentos da política regulatória: saúde suplementar; prestadores privados do SUS; e as próprias relações entre níveis de governo no SUS.

Com relação à saúde suplementar, a Lei 9.656 criou organismos colegiados internos ao governo, como o CNSP e o CONSU, e organismos de caráter amplo e societário, como a Câmara de Saúde Complementar, que segue o modelo multipartite típico. A importância de cada organismo no jogo regulatório não está plenamente estabelecida em termos políticos, porém a Câmara, onde se concretiza o padrão regulatório tripartite, vem desempenhando efetivamente funções de pactuação e competição entre os agentes e grupos de interesses ativos na política e tende a adquirir centralidade na implementação da política. No modelo de agência vitorioso está reservado o espaço de intervenção da Câmara de Saúde Suplementar.

$\mathrm{O}$ tripartismo se manifesta, neste caso, de modo bastante instituído, na regulação de funções internas ao SUS, como no caso dos prestadores privados do sistema e nas transferências intergovernamentais. O Conselho Nacional de Saúde - CNS - exerce funções de formulação e regulação em competição com os núcleos governamentais e sua influência varia conforme as coalizões governamentais e no próprio conselho. Uma instância competidora significativa com relação ao CNS é a Comissão Intergestores Tripartite - CIT, cuja composição envolve apenas representantes governamentais. A operação política da CIT é facilitada pela menor abrangência de sua representação governamental, porém esta economia em custos decisórios implica em menor sustentabilidade de suas resoluções. A competição por centralidade no processo de formulação e regulação política entre a burocracia ministerial, o CNS e a CIT, reproduz-se com intensidade variável no nível estadual e municipal por meio de organismos similares (Comissões Intergestores Bipartite; Conselho Estadual de Saúde e Conselho Municipal de Saúde). O tripartismo representa uma inovação da política de saúde no Brasil, consolidando-se ao longo da década de noventa e seus obstáculos mais comuns referem-se ao domínio técnico especializado pelos seus membros (dependente da difusão de informações) e à dinâmica interna das organizações que afetam a disposição de seus representantes ao comportamento cooperativo (dependente da dinâmica política e da formação de coalizões) .

Com relação à auto-regulação contratada, o padrão mais representativo é o da acreditação hospitalar, pelo qual o Ministério da Saúde efetuou investimentos, através do programa REFORSUS, no sentido de induzir organismos privados a formarem a Organização Nacional de Acreditação ONA. Os resultados esperados estão na criação de um padrão de qualidade no mercado, reduzindo os custos da regulação burocrática em nome de maior ordenamento na competição entre os hospitais por recursos públicos $e$ privados. Em que pese a participação do Conass e do Conasems entre os fundadores da ONA, representando elementos estatais na política implementada, é esperada uma migração do modelo para uma auto- 
regulação laissez-faire mais típica.

Por fim, a auto-regulação mais tipicamente observada no setor saúde no Brasil diz respeito aos conselhos profissionais que, pela elaboração de normas e pelo estabelecimento de processos éticos, regulam a prática profissional individual. O Conselho Federal de Medicina é a estrutura mais evidente da auto-regulação profissional, embora organismos semelhantes existam para os demais profissionais como enfermeiros e odontólogos, cujas entidades são ativas na política setorial. Ainda se observa um componente estatal relacionado aos conselhos profissionais como resultado da legislação corporativa brasileira, que considera estes organismos parte integrante do aparelho de Estado. Este aspecto é paradoxal em termos de um sistema de auto-regulação, porém a autonomia organizacional obtida após a redemocratização política do país e a autonomia profissional dos médicos e odontólogos, por exemplo, definem sua característica na política regulatória. Atualmente está em curso a reforma da legislação que regulamenta o funcionamento destes conselhos e a tendência observada aponta para o reforço de sua autonomia frente às instituições de estado e de seu caráter auto-regulador.

As tendências apontadas neste tópico final apresentam consistência com o desenvolvimento da política de regulação do setor saúde no Brasil e servem de roteiro para estudos empíricos necessários no estágio atual das reformas e inovações em curso.

Referências bibliográficas

ALMEIDA, F.G. Conjuntura Econômica, jan., set., dez., p.5-7, 1998.

ARMSTRONG, M., COWAN, S., VICKERS, J. Regulatory reform: economic analysis and british experience. Cambridge: MIT, 1995.

AYRES, I., BRAITHWAITE, J. Responsive regulation: transcending the deregulation debate. Oxford: Oxford University Press, 1992.

BAER, W., MACDONALD, C. Um retorno ao passado? A privatização de empresas de serviços públicos no Brasil: o caso do setor de energia elétrica. Políticas Públicas e Planejamento, n.16, p.5-38, 1997.

BANCO MUNDIAL. O estado em um mundo em transformação. Brasília, 1997.

BRASIL/PRESIDENTE. Plano diretor da reforma do aparelho do estado. Brasília, 1995.

CONJUNTURA ECONÔMICA. Seguro-saúde: o mercado que mais cresce, maio/1998, p.30-34.

COSTA, N. R. Reforma administrativa, previsibilidade decisória e eficiência do estado. In:

PETRUCCI, V. \& SCHWARZ, L. Administração pública gerencial: a reforma de 1995.

Brasília: Universidade de Brasília/ENAP, 1999. p.223-39.

NUNES, E. A gramática política do Brasil: clientelismo e insulamento burocrático. Rio de Janeiro: Jorge Zahar, 1997.

PINHEIRO, A. C. Impactos microeconômicos da privatização no Brasil, Pesqu. Planej. Econômico, v.26, n.3, p.357-98, 1996.

ROBINSON, R., STEINER, A. Managed health care: US evidence and lessons for the National Health Service. London: Open University Press, 1998.

SILBERMAN, B. S. Cages of reason: the rise of the rational state in France, Japan, the United States, and Great Britain. Chicago: The University of Chicago Press, 1993. 


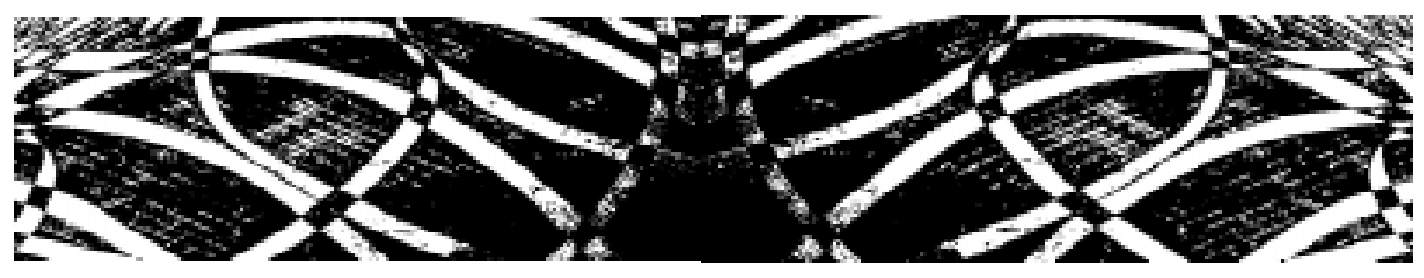

RIBEIRO, J.M, COSTA, N.R., SILVA, P.L.B. Política de Salud en Brasil y etrategias reguladoras en ambiente de cambios tecnológicos, Interface - Comunicação, Saúde, Educação, v.4 , n.6, 2000.

Este texto discute tales políticas en relación al mercado de las organizaciones proveedoras privadas y de los prestadores cuyos servicios adquieren las administraciones públicas locales. Apunta las singularidades del sector de salud por comparación a las industrias sometidas a los nuevos regiménes, como telecomunicaciones, electricidad y petróleo y se afirma la tendencia al uso de políticas reguladoras responsivas y concertadas junto a los sistemas públicos y privados.

PALAVRAS CLAVE: política de salud; innovación organizacional; modelos organizacionales; desarrollo tecnológico; administradión pública; legislación. 